\title{
Calcium and Magnesium Concentration of Inbred and Hybrid Broccoli Heads
}

\author{
Mark W. Farnham ${ }^{1}$ \\ U.S. Department of Agriculture, Agricultural Research Service, U.S. Vegetable Laboratory, 2875 \\ Savannah Highway, Charleston, SC 29414 \\ Michael A. Grusak \\ U.S. Department of Agriculture, Agricultural Research Service, Children's Nutrition Research Center, \\ Department of Pediatrics, Baylor College of Medicine, Houston, TX 77030 \\ Min Wang \\ U.S. Department of Agriculture, Agricultural Research Service, U.S. Vegetable Laboratory, 2875 \\ Savannah Highway, Charleston, SC 29414
}

\begin{abstract}
AdDitional INDEX words. Brassica oleracea, Italica Group, doubled-haploids, nutrition
Abstract. Broccoli (Brassica oleracea L., Italica Group) is a good vegetable source of Ca and Mg, two critical minerals in human nutrition. Studies have shown that bioavailability of Ca from broccoli is comparable to that from milk. Thus, broccoli is an important alternative source of $\mathrm{Ca}$ in segments of the population that consume limited amounts of dairy products. Essentially nothing is known about the genetic influence on variation in Ca or Mg concentration of broccoli heads. Thus, the goal of this research was to examine variation in $\mathrm{Ca}$, and also $\mathrm{Mg}$ concentrations, in a collection of USDA inbreds and commercial $F_{1}$ hybrids. In 1996 and 1997 field studies, significant differences among inbred entries and among hybrid entries were observed for $\mathrm{Ca}$ and $\mathrm{Mg}$ concentrations of broccoli heads. With hybrids and inbreds, mean head Ca concentrations were $\approx 3.0 \mathrm{mg} \cdot \mathrm{g}^{-1} \mathrm{dry}$ weight $(\mathrm{DW})$, and entries with lowest and highest Ca concentrations differed $>2$-fold. Mean Mg concentrations of hybrid heads was $2.3 \mathrm{mg} \cdot \mathrm{g}^{-1} \mathrm{DW}$ (range 1.8 to 2.6 ) and $2.8 \mathrm{mg} \cdot \mathrm{g}^{-1} \mathrm{DW}$ (range 2.2 to 3.7) in 1996 and 1997, respectively. Inbred lines had mean head $\mathrm{Mg}$ concentrations of 2.0 and $2.6 \mathrm{mg} \cdot \mathrm{g}^{-1} \mathrm{DW}$ in the two respective years and ranges in concentration were similar as for hybrids. Analysis of variance indicated significant environment and entry by environment effects for Ca and Mg concentrations of hybrids. With inbreds, a significant entry by environment effect for Ca concentration and environment effect for Mg concentration was also observed. Significant environment and entry by environment effects indicate that the environmental influence on phenotypic expression of Ca and Mg concentrations may complicate genetic improvement of head mineral concentration.
\end{abstract}

Calcium and Mg nutrition in humans are important concerns because of the critical role that both $\mathrm{Ca}$ and $\mathrm{Mg}$ play in bone development and structure, as well as in cellular metabolism (Linder, 1991). Inadequate $\mathrm{Ca}$ in diets, especially in children, could lead to increased risk of osteoporosis in later life (Johnston et al., 1992). Although the impact of inadequate $\mathrm{Mg}$ is not as significant or as well recognized as it is for $\mathrm{Ca}$, it remains a concern, especially with children and adolescents, who have been shown to intake less Mg than recommended (Shils, 1996).

Dairy products supply a majority of human dietary $\mathrm{Ca}$ and $\mathrm{Mg}$ requirements; however, certain vegetables can also provide significant amounts of these minerals. Green leafy vegetables are relatively good sources of $\mathrm{Ca}$ but the bioavailability of this $\mathrm{Ca}$ to humans depends on the vegetable species. Spinach (Spinacia oleracea $\mathrm{L}$.) is an example of a vegetable that has a high $\mathrm{Ca}$ concentration, but this occurs in association with oxalates that bind $\mathrm{Ca}$ and decrease bioavailability of the mineral (Heaney et al., 1988). Other vegetables, like kale (Brassica oleracea, Acephala Group), bok choy (Brassica rapa L., Chinensis Group), and

Received for publication 21 May 1999. Accepted for publication 15 Feb. 2000. This project was funded in part with federal funds from the USDA-ARS under Cooperative Agreement 58-6250-6-001. We acknowledge technical assistance of Eric Gomperts. The contents of this publication do not necessarily reflect the views or policies of the USDA, nor does mention of trade names, commercial products, or organizations imply endorsement by the U.S. Government. The cost of publishing this paper was defrayed in part by the payment of page charges. Under postal regulations, this paper therefore must be hereby marked advertisement solely to indicate this fact.

${ }^{1}$ To whom reprint requests should be addressed. broccoli (Brassica oleracea, Italica Group), have relatively high $\mathrm{Ca}$ concentrations and low levels of constituents that render $\mathrm{Ca}$ unavailable. Heaney et al. (1993) found bioavailability of $\mathrm{Ca}$ in these cruciferous vegetables to be equal $(\approx 30 \%)$ to that of milk. Largely due to the increasing popularity of broccoli (Fairchild, 1999), it has been cited in the popular press as one of the best vegetable sources of $\mathrm{Ca}$ in the human diet. Less is known about the human bioavailability of $\mathrm{Mg}$ from vegetables, and Shils (1996) suggested that additional quantitative information is needed to better understand how much of this mineral is supplied by food sources.

Only a few studies have examined genetic variation in $\mathrm{Ca}$ or $\mathrm{Mg}$ content for a vegetable species within the context of human nutrition. Quintana et al. (1996) have shown with snap bean (Phaseolus vulgaris L.) that significant genetic variation for pod Ca concentration is present in the crop and that enhancement of $\mathrm{Ca}$ levels may be feasible. Those authors observed significant additive genetic variance for pod $\mathrm{Ca}$ concentration and obtained a narrow sense heritability estimate of 0.5 for this trait. In examining green bean cultivars with divergent pod Ca concentrations, Grusak et al. (1996) and Grusak and Pomper (1999) showed that enhancements in whole-plant net $\mathrm{Ca}$ influx during pod growth and in xylem transport of absorbed $\mathrm{Ca}$ to developing pods might both contribute to higher Ca concentrations in pods of some cultivars.

Studies focused on plant nutrition and vegetable production also provide information regarding the Ca makeup of vegetables. For example, Ca nutrition is critical for optimal fruit development in tomato (Lycopersicon esculentum Mill.) and prevention of 
blossom end rot, and impact of cultivar on occurrence of blossom end rot has been studied thoroughly in this crop. Greenleaf and Adams (1969), Giordano et al. (1982), and Li and Gabelman (1990) cited divergent cultivars that exhibit different Ca use and incidence of blossom end rot. Greenleaf and Adams (1969) concluded that some tomato cultivars that are resistant to blossom end rot exhibit a greater efficiency in accumulating $\mathrm{Ca}$ in fruit while other resistant cultivars have a lower requirement for $\mathrm{Ca}$ within fruit for normal development. Behling et al. (1989) studied one Caefficient tomato line and concluded that this line exhibited a $\mathrm{Ca}$ distribution system that was independent of transpiration. Giordano et al. (1982) showed that some Ca efficient tomato lines have roots that are more effective in removing $\mathrm{Ca}$ from solution while other lines are better able to utilize $\mathrm{Ca}$ following absorption; they concluded that efficiency of $\mathrm{Ca}$ utilization by tomato was controlled by simple additive-dominance systems. Li and Gabelman (1990) obtained high $(\approx 50 \%)$ broad-sense heritability and moderately high $(\approx 70 \%)$ narrow-sense heritabilities for total dry matter accumulation in a $\mathrm{Ca}$ stress environment; this suggested that heritable differences in $\mathrm{Ca}$ efficiency among tomato lines warranted the use of some of these lines in a breeding program.

Although broccoli is an excellent source of $\mathrm{Ca}$ and $\mathrm{Mg}$, very little is known about the dynamics of these minerals in this crop. The U.S. Dept. of Agriculture (USDA) Nutrient Database for Standard Reference [USDA-Agricultural Research Service (ARS), 1998] cites values for Ca and $\mathrm{Mg}$ of 4.8 and $2.5 \mathrm{mg} \cdot \mathrm{g}^{-1} \mathrm{dry}$ weight (DW), respectively, for broccoli, but there is no information about cultivars, environments, head characteristics at harvest, or other pertinent factors to describe the broccoli sample(s) from which these values were derived. Thus, a primary objective of this research was to determine if phenotypic variation for $\mathrm{Ca}$ and $\mathrm{Mg}$ concentration of broccoli heads exists among commercial hybrids and among USDA inbreds. In addition, we wanted to examine interrelationships between $\mathrm{Ca}$ and $\mathrm{Mg}$ concentrations and broccoli head weight and maturity.

\section{Materials and Methods}

Plant material. Twenty-seven commercial hybrid cultivars including Green Valiant, Arcadia, Ninja, Patriot, Greenbelt, Emerald City, Sultan, and Marathon from Sakata Inc. (Salinas, Calif.); Olympus, Liberty, Viking, Captain, Major, Pirate, and Packman from Peto Seed Co. (Saticoy, Calif.); High Sierra, Sabre, and Baron from Asgrow Seed Co. (San Juan Bautista, Calif.); Everest and Signal from Rogers Seed Co. (Gilroy, Calif.); Pinnacle, Headline, Zeus, and Charade from Takii Seed (Salinas, Calif.); Eureka from Stokes (Buffalo, N.Y.); Excelsior from Harris Moran (Modesto, Calif.); and Claudia from Ferry Morse (San Juan Bautista, Calif.) were selected for evaluation in field trials. This pool of hybrids was selected to represent a diverse phenotypic and genotypic array of commercial broccoli grown in the United States. A second pool of materials evaluated in this research included 19 inbred (doubled-haploid) lines developed at the U.S. Vegetable Laboratory in Charleston, S.C. These inbreds were developed using standard techniques of anther culture (Farnham, 1998). Inbred designations and their parental source are as follows: USVL013, 020, 071, and 072 derived from 'Everest'; USVL021, 022, 028, and 070 from 'Futura' (Asgrow Seed Co.); USVL030 and 031 from 'Green Valiant'; USVL033, 036, 042, and 045 from 'High Sierra'; USVL 048, 049, and 073 from 'Marathon'; USVL062 from 'Sultan'; and USVL074 from 'Viking'. All inbred seed were produced onsite at the U.S.
Vegetable Laboratory. This pool of inbreds was selected to represent a diverse phenotypic and genotypic array of broccoli that is likely to occur in a U.S. broccoli breeding program.

Plant Culture. In 1996, due to limited seed supplies of inbreds compared to hybrids, two trials, one with the hybrid entries and a smaller one with the inbred entries were conducted in adjacent sections (rows) of the same field. Hybrids and inbreds were seeded to trays in a greenhouse at Charleston during the first and second weeks of August, respectively. Hybrid seedlings were transplanted to the field in Charleston on $28 \mathrm{Aug}$. and inbreds were transplanted 7 Sept. Hybrids were grown in a randomized complete block design with three replications, and each plot was a single row of 20 plants. Spacing between rows and between plants within a row was 102 and $15 \mathrm{~cm}$, respectively. Inbreds were grown in a randomized complete block design with two replications and 6 to 10 plants per plot using the same spacing as hybrids. All cultural practices (e.g., cultivation and irrigation) were standard for local conditions (Cook and Ezell, 1983) and the same for both trials. The soil type at the Charleston site is a Yonges loamy sand (fine loamy mixed, thermic Albaqualfs). Prior to planting in 1996, a standard soil test indicated a $\mathrm{pH}$ of 5.5 and $\mathrm{Ca}$ and $\mathrm{Mg}$ levels of 1261 and $100 \mathrm{~kg} \cdot \mathrm{ha}^{-1}$, respectively. To insure that N, P, and $\mathrm{K}$ would not be limiting in this trial, $1120 \mathrm{~kg} \cdot \mathrm{ha}^{-1} 10 \mathrm{~N}-4.3 \mathrm{P}-$ $8.3 \mathrm{~K}$ granular fertilizer was applied to the field prior to transplanting, and plots were also side-dressed with $168 \mathrm{~kg} \cdot \mathrm{ha}^{-1}$ ammonium nitrate at $\approx 3$ and 6 weeks after transplanting.

In 1997, hybrids and inbreds were both seeded to the greenhouse during the first week of August. Seedlings of all hybrid and inbred entries were transplanted to the field on 27 Aug. The experimental design for hybrids and inbreds was a randomized complete block with three replications. Hybrids had 20 plants per plot, but inbreds had only 6 to 10 . Spacing, cultural practices, and fertilization were the same as the previous year, and although the trials were conducted on a different field (at the same experiment station) than the one used before, the soil type was the same. About $1120 \mathrm{~kg} \cdot \mathrm{ha}^{-1}$ dolomitic limestone was applied to the field $\approx 6$ months before initiating the trial. At transplanting, a soil test of this second field indicated a pH of 6.0 and $\mathrm{Ca}$ and $\mathrm{Mg}$ levels of 910 and $195 \mathrm{~kg} \cdot \mathrm{ha}^{-1}$, respectively.

HEAD HARVEST. As plants approached maturity in both years, the plots were evaluated every 2 to $3 \mathrm{~d}$ until all heads were observed. Hybrid and inbred heads were considered mature for harvest when head diameter reached 10 to $12 \mathrm{~cm}$, and sampling of all entries was done when heads attained this size range or harvest stage. With hybrids, four random heads per plot were collected, cut to a $10 \mathrm{~cm}$ length, and bulked for subsequent $\mathrm{Ca}$ and $\mathrm{Mg}$ analysis. With inbreds, three heads were collected; these also were cut to a $10 \mathrm{~cm}$ length and bulked for mineral analysis. Sampling date of heads for each hybrid or inbred entry was recorded to determine the mean number of days from transplanting to harvest stage (DTH).

SAMPLE PREPARATION AND MINERAL ANALYSIS. All heads cut for mineral analysis were placed in paper bags and dried at $\approx 60{ }^{\circ} \mathrm{C}$ until samples reached a constant DW; samples were then weighed. For each plot, average head weight was calculated by dividing total weight of harvested heads by the number of heads. Dried heads were ground to a $0.5-\mathrm{mm}$ sieve size using a cutting mill (model SM1; Brinkmann Instruments, Westbury, N.Y.) to homogenize each sample. Two subsamples for each plot entry were wet digested and the digestate resuspended as described in Grusak (1994). Total Ca content or Mg content per gram DW of sample was determined using atomic absorption spectrophotom- 
etry (AAS) (model 2100; Perkin Elmer, Norwalk, Conn.). Values for replicate subsamples were averaged to obtain single $\mathrm{Ca}$ and $\mathrm{Mg}$ concentrations for each plot.

Statistical Analysis. For statistical analysis, hybrids were treated separately from inbreds. The two hybrid trials were first analyzed separately to examine entry effects on mineral concentrations and other traits (e.g., mean head weight) in each environment and then analyzed together to examine environment and entry by environment interaction effects. Likewise, the two inbred trials were analyzed separately and then together for the same reasons. Analysis of variance (ANOVA) was performed using Proc GLM of SAS (release 6.12, SAS Institute, Inc., Cary, N.C.). Entry means were compared with Fisher's protected LSD. Pearson correlation coefficients were calculated among all pairings of mean head weight, mean DTH, head Ca concentration, and head $\mathrm{Mg}$ concentration for inbred and hybrid entries.
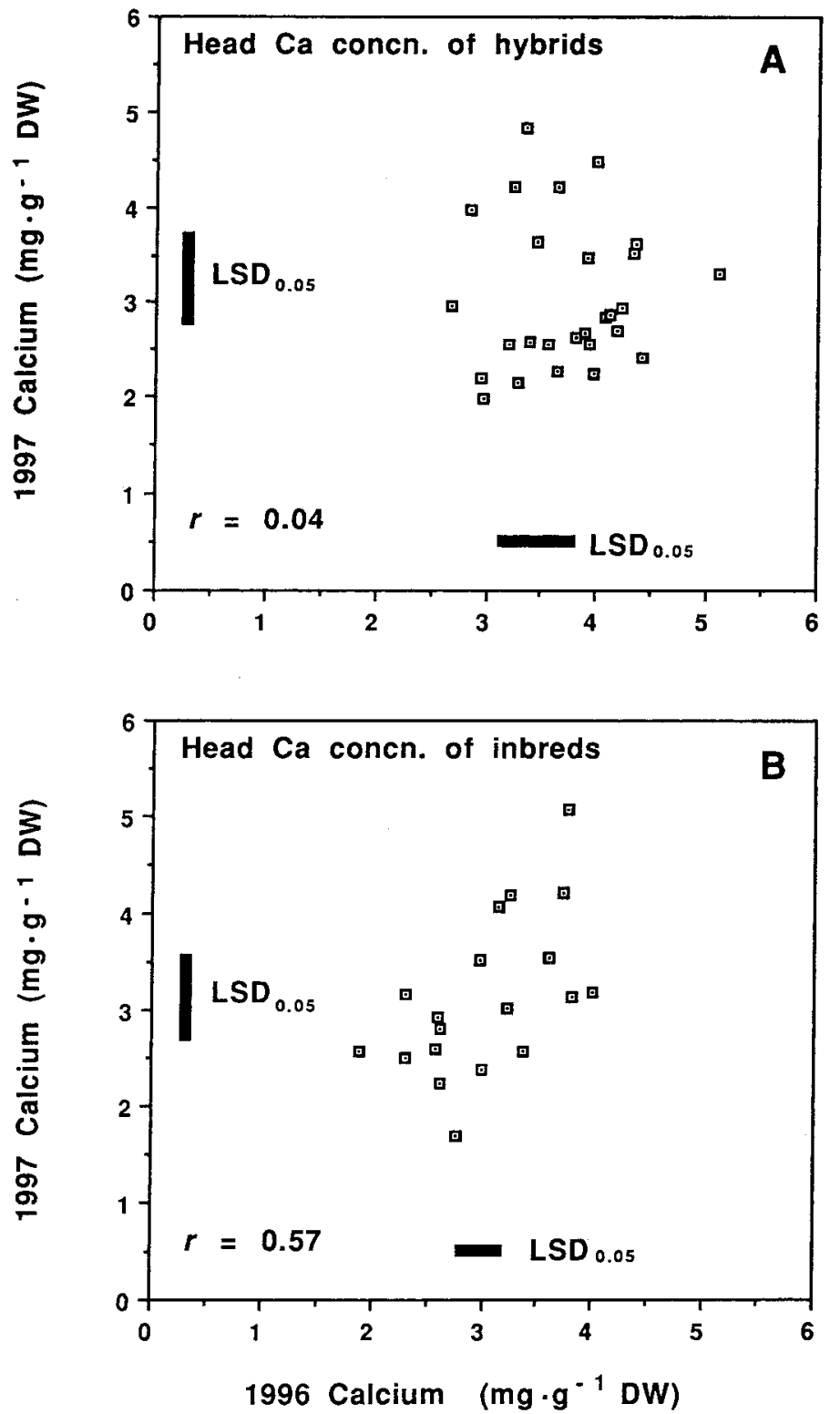

Fig. 1. Mean head Ca concentration on a dry weight basis of (A) hybrid and (B) inbred broccoli entries in 1996 and 1997 environments. Horizontal bars represent the $\mathrm{LSD}_{0.05}$ for mean separation of hybrids and inbreds grown in 1996 and vertical bars represent the $\mathrm{LSD}_{0.05}$ for mean separation of entries grown in 1997; $r$ values represent Pearson correlation coefficients between 1996 and 1997 entry means.

\section{Results}

In hybrid and inbred trials, broccoli entries differed significantly in head $\mathrm{Ca}$ and $\mathrm{Mg}$ concentrations on a DW basis in the 1996 and 1997 environments. With hybrids, mean Ca concentration was $3.7 \mathrm{mg} \cdot \mathrm{g}^{-1} \mathrm{DW}$ (range of 2.7 to 5.1 ) in 1996 and $3.0 \mathrm{mg} \cdot \mathrm{g}^{-1} \mathrm{DW}$ (range of 2.0 to 4.8) in 1997 (Fig. 1A). Inbreds had means of 3.0 $\mathrm{mg} \cdot \mathrm{g}^{-1} \mathrm{DW}$ (range 1.9 to 4.0 ) in 1996 and $3.1 \mathrm{mg} \cdot \mathrm{g}^{-1} \mathrm{DW}$ (range 1.7 to 5.1) in 1997 (Fig. 1B). Mean Mg concentrations of hybrid heads were $2.3 \mathrm{mg} \cdot \mathrm{g}^{-1} \mathrm{DW}$ (range of 1.8 to 2.6 ) and $2.8 \mathrm{mg} \cdot \mathrm{g}^{-1} \mathrm{DW}$ (range 2.2 to 3.7) in 1996 and 1997, respectively (Fig. 2A). Inbred lines had mean $\mathrm{Mg}$ concentrations of 2.0 (range of 1.6 to 2.4) and $2.6 \mathrm{mg} \cdot \mathrm{g}^{-1} \mathrm{DW}$ (range of 2.0 to 3.3 ) in the two respective years (Fig. 2B). When hybrid results from both environments were combined for ANOVA, significant environmental, entry, and entry by environment effects were observed for both head $\mathrm{Ca}$ and Mg concentrations (Table 1 ). With inbreds, entry and entry by environment effects were significant for Ca concentration, while
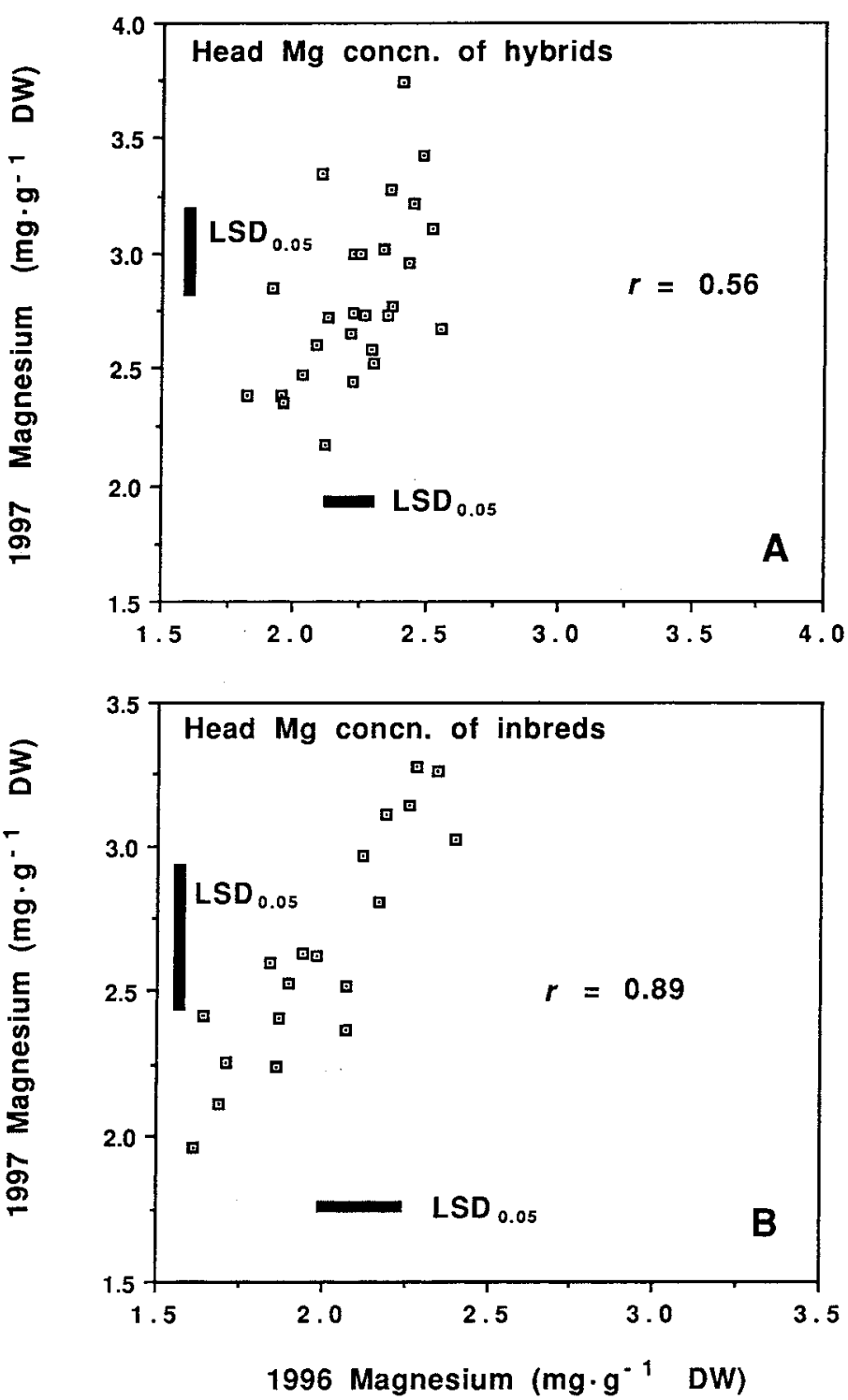

Fig. 2. Mean head Mg concentration on a dry weight basis of (A) hybrid and (B) inbred broccoli entries in 1996 and 1997 environments. Horizontal bars represent the $\mathrm{LSD}_{0.05}$ for mean separation of hybrids and inbreds grown in 1996 and vertical bars represent the $\mathrm{LSD}_{0.05}$ for mean separation of entries grown in 1997; $r$ values represent Pearson correlation coefficients between 1996 and 1997 entry means. 
Table 1. Analysis of variance for environment (Env) and entry effects on head Ca and $\mathrm{Mg}$ concentrations, head weight, and days from transplant to harvest (DTH) of hybrid and inbred sets grown in two environments.

\begin{tabular}{|c|c|c|c|c|c|c|}
\hline \multirow[b]{2}{*}{$\begin{array}{l}\text { Entry } \\
\text { type }\end{array}$} & \multirow[b]{2}{*}{ Effect } & \multirow[b]{2}{*}{$\mathrm{df}$} & \multicolumn{4}{|c|}{ Mean square } \\
\hline & & & $\begin{array}{c}\mathrm{Ca} \\
\text { concn }\end{array}$ & $\begin{array}{c}\mathrm{Mg} \\
\text { concn }\end{array}$ & $\begin{array}{c}\text { Head } \\
\text { wt }\end{array}$ & DTH \\
\hline \multirow[t]{6}{*}{ Hybrid } & Env & 1 & $18.24^{*}$ & $13.33^{* *}$ & $28.72^{*}$ & 244.45 \\
\hline & Rep (Env) & 4 & $2.08^{* * * *}$ & 0.08 & 3.02 & $44.83^{*}$ \\
\hline & Entry & 26 & $1.44^{* * * *}$ & $0.39^{* *}$ & $7.61^{* * * *}$ & $620.83^{* * *}$ \\
\hline & Entry $\times$ Env & 26 & $1.32^{* * * *}$ & $0.15^{* *}$ & $6.31^{* * * *}$ & $50.66^{* * *}$ \\
\hline & Error & 104 & 0.27 & 0.04 & 1.61 & 17.68 \\
\hline & Total & 161 & & & & \\
\hline \multirow[t]{6}{*}{ Inbred } & Env & 1 & 0.24 & $9.63^{*}$ & $294.56^{* * *}$ & 102.74 \\
\hline & Rep (Env) & 3 & 0.08 & $0.29^{* * *}$ & 5.38 & 48.08 \\
\hline & Entry & 18 & $2.16^{* * * *}$ & $0.53^{* * *}$ & $34.76^{* * *}$ & $1151.68^{* * * *}$ \\
\hline & Entry $\times$ Env & 18 & $0.57^{*}$ & 0.05 & $7.58^{* *}$ & $71.51^{* *}$ \\
\hline & Error & 54 & 0.28 & 0.07 & 3.29 & 24.55 \\
\hline & Total & 94 & & & & \\
\hline
\end{tabular}

${ }^{* * * * * * * *}$ Significant at $P \leq 0.05,0.01$, or 0.001 , respectively.

Table 2. Correlation of broccoli entry means for head Ca concentration, head Mg concentration, head weight, and days from transplant to harvest (DTH) in the 1996 (above the diagonal) and 1997 (below the diagonal) environments.

\begin{tabular}{|c|c|c|c|c|c|}
\hline \multirow[b]{2}{*}{$\begin{array}{l}\text { Entry } \\
\text { type }\end{array}$} & \multirow[b]{2}{*}{ Trait } & \multicolumn{4}{|c|}{ Trait } \\
\hline & & $\begin{array}{c}\mathrm{Ca} \\
\text { concn }\end{array}$ & $\begin{array}{c}\mathrm{Mg} \\
\text { concn }\end{array}$ & $\begin{array}{c}\text { Head } \\
\text { wt }\end{array}$ & DTH \\
\hline \multirow[t]{4}{*}{ Hybrid } & Ca concn & --- & 0.18 & $-0.46^{*}$ & -0.17 \\
\hline & Mg concn & $0.58^{* *}$ & --- & $-0.63^{* *}$ & $-0.45^{*}$ \\
\hline & Head wt & $-0.69^{* *}$ & $-0.68^{* *}$ & --- & $0.43^{*}$ \\
\hline & DTH & $-0.66^{* *}$ & $-0.82^{* * *}$ & $0.71^{* *}$ & --- \\
\hline \multirow[t]{4}{*}{ Inbred } & Ca concn & --- & $0.63^{* *}$ & -0.27 & -0.20 \\
\hline & $\mathrm{Mg}$ concn & $0.50^{*}$ & --- & $-0.56^{*}$ & $-0.56^{*}$ \\
\hline & Head wt & 0.02 & $-0.46^{*}$ & --- & $-0.71^{* *}$ \\
\hline & DTH & -0.42 & $-0.80^{* *}$ & $0.58^{* *}$ & --- \\
\hline
\end{tabular}

**** Significant at $P \leq 0.05$ or 0.01 , respectively, of a greater absolute value of the correlation coefficient highlighted.

Table 3. Hybrid and inbred entries with relatively consistent high or low head Ca and Mg concentrations on a dry weight (DW) basis in the 1996 and 1997 environments.

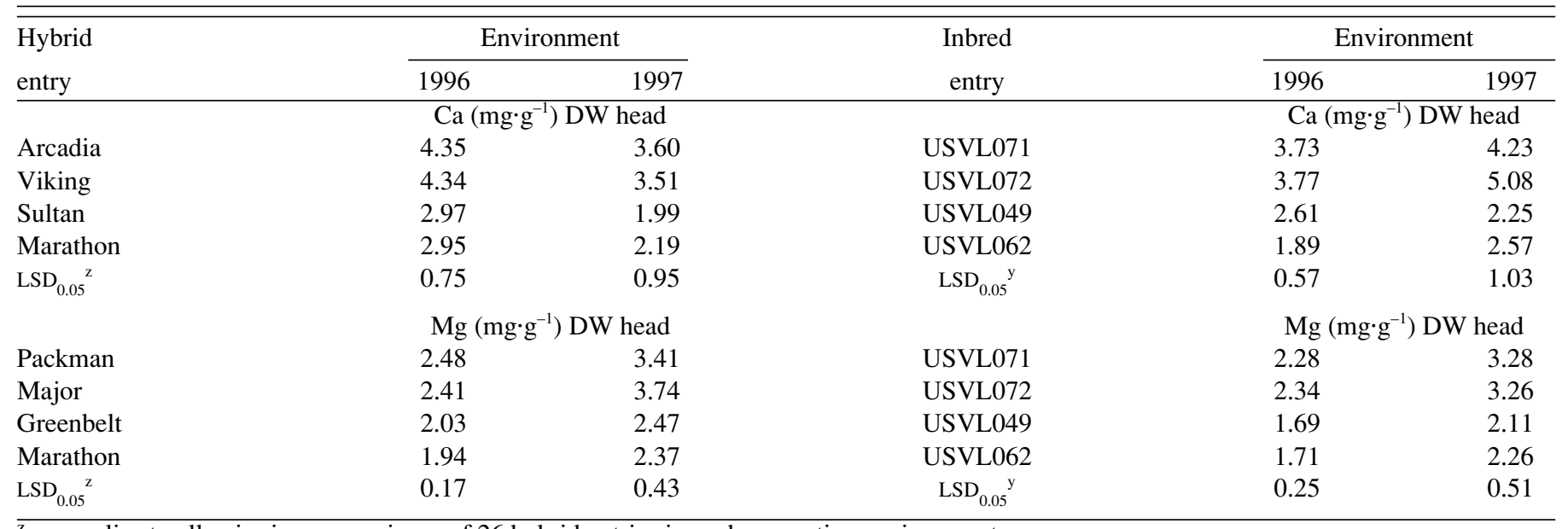

${ }_{\mathrm{Z}} \mathrm{LSD}$ applies to all pairwise comparisons of 26 hybrid entries in each respective environment.

$\mathrm{y}_{\mathrm{LSD}}$ applies to all pairwise comparisons of 19 inbred entries in each respective environment.

entry and environment effects were significant for Mg concentration (Table 1).

Hybrid entry means for head $\mathrm{Mg}$ and Ca concentrations were not correlated with each other in 1996 , but were positively correlated in 1997 (Table 2). Calcium and Mg concentrations of hybrids were significantly $(P<0.05)$ and negatively correlated with head weight in 1996 and 1997 trials. Similarly, Mg concentration was negatively correlated with DTH in 1996 and 1997 
hybrid tests. Calcium concentration was negatively correlated with DTH in 1997 but not in 1996.

Calcium and $\mathrm{Mg}$ concentrations of inbred heads were positively correlated with one another in both environments (Table 2). In addition, $\mathrm{Ca}$ concentration of inbreds was not correlated with head weight or DTH in either environment, while Mg concentration was negatively correlated with both of these characters in both environments.

Among hybrid entries, certain cultivars (e.g., 'Arcadia') exhibited relatively high $\mathrm{Ca}$ concentrations in both environments, while certain others (e.g., 'Marathon') were always low (Table 3). Likewise, certain hybrid entries (e.g., 'Packman') were high in Mg concentration in both environments, but others (e.g., 'Marathon') were always low in $\mathrm{Mg}$ (Table 3). Since head $\mathrm{Ca}$ and $\mathrm{Mg}$ concentrations of hybrids were not consistently correlated with one another in the different environments, entries with high $\mathrm{Ca}$ concentration did not always have high $\mathrm{Mg}$ concentration, and entries with low $\mathrm{Ca}$ did not necessarily have low $\mathrm{Mg}$.

With inbreds, one can also identify certain entries exhibiting high or low head $\mathrm{Ca}$ and $\mathrm{Mg}$ concentrations in both environments (Table 3). Since the two mineral concentrations were significantly and positively correlated in both environments, inbreds (e.g., USVL071) with high Ca concentration typically had high Mg concentration, and other inbreds (e.g., USVL049) with low $\mathrm{Ca}$ concentration also had low $\mathrm{Mg}$ concentration.

\section{Discussion}

Nearly all broccoli heads consumed in the U.S. are harvested from commercial $F_{1}$ hybrids. Our results, based on a range of these commercially available hybrids, clearly indicate that variation in head $\mathrm{Ca}$ and $\mathrm{Mg}$ concentrations should be expected among hybrids in a given environment (Figs. 1 and 2). We are unaware of previous reports citing phenotypic variation for $\mathrm{Ca}$ and $\mathrm{Mg}$ concentration of broccoli heads as demonstrated herein. Although the USDA Nutrient Database for Standard Reference (USDA-ARS, 1998) provides mean values for $\mathrm{Ca}$ and $\mathrm{Mg}$ concentration in broccoli grown in the U.S. (4.8 and $2.5 \mathrm{mg} \cdot \mathrm{g}^{-1} \mathrm{DW}$, respectively), our results demonstrate that choice of hybrid can have a very significant impact on the concentration of these minerals in the harvested vegetable. In addition, our measurements for $\mathrm{Ca}$, in particular, indicate that the database Ca value of $4.8 \mathrm{mg} \cdot \mathrm{g}^{-1} \mathrm{DW}$ broccoli head is probably high relative to much of the broccoli that would be available to consumers. Averaged over both years, Ca was observed at $3.4 \mathrm{mg} \cdot \mathrm{g}^{-1} \mathrm{DW}$ broccoli head for hybrids. That average is very close to a value of 3.5 $\mathrm{mg} \cdot \mathrm{g}^{-1} \mathrm{DW}$ recently reported by Lucarini et al. (1999) who examined a single sample of broccoli (unidentified cultivar) purchased from a store.

Significant environment and entry by environment effects indicate that the environment plays an important role in expression of mineral concentration in broccoli hybrid heads. This finding was not surprising since $\mathrm{Ca}$ and $\mathrm{Mg}$ must be acquired from the environment. However, the magnitude of these effects was unexpected when one considers that the two environments studied in this experiment had some similarities (i.e., different fields at the same location and two fall seasons in different years). It seems safe to assume that if one were to grow the same hybrids utilized in these studies in more diverse locations, regions, or seasons, one could expect even larger environmental and entry by environment effects than were observed. Although neither $\mathrm{Ca}$ or $\mathrm{Mg}$ was considered limiting for broccoli growth in either environment described in this work (based on standard soil tests), the field used in 1997 was limed 6 months prior to transplanting. This liming increased soil $\mathrm{pH}$ over the first year and very likely altered $\mathrm{Ca}$ and $\mathrm{Mg}$ dynamics in the soil and at the soil/plant interface. This might explain the different $\mathrm{Ca}$ and $\mathrm{Mg}$ concentrations for a given hybrid in the two environments. Alternatively, another environmental factor like humidity could have had an influence on tissue mineral levels. Grusak and Pomper (1999) reported that alteration of pod transpiration with variable humidity treatments had a significant effect on $\mathrm{Ca}$ accumulation in snap bean pods. Broccoli heads are transpiring organs, and it is possible that variable head transpiration rates occurring in the different environments and at different times in each of the environments might have caused some variation (i.e., environmental as well as entry by environment) in levels of $\mathrm{Ca}$ accretion in sampled heads.

As observed with hybrids, variation in head $\mathrm{Ca}$ and $\mathrm{Mg}$ concentrations among inbreds was highly significant, and the inbred ranges for head $\mathrm{Ca}\left(\approx 2\right.$ to $\left.5 \mathrm{mg} \cdot \mathrm{g}^{-1} \mathrm{DW}\right)$ and $\mathrm{Mg}\left(\approx 2\right.$ to $\left.3.5 \mathrm{mg} \cdot \mathrm{g}^{-1} \mathrm{DW}\right)$ were similar to those for hybrids. However, the environment had less of an effect on $\mathrm{Ca}$ and $\mathrm{Mg}$ concentrations of heads harvested from inbreds compared to concentrations for hybrids (Table 1). In general, relative phenotypic expression of head $\mathrm{Ca}$ and $\mathrm{Mg}$ concentrations of inbreds showed some consistency between the two environments, but relative expression in hybrids was not consistent. (Figs. 1 and 2). Studies with inbred lines of snap bean have shown significant phenotypic variation for pod Ca concentration(Quintana et al., 1996), and likewise, work with inbred tomatoes has shown significant phenotypic variation in fruit Ca concentration in this crop (Giordanoetal., 1982; Greenleaf and Adams, 1969; Liand Gabelman, 1990).

Phenotypic variation in mineral concentration could be due to genetic variation among entries for capacity to take up minerals from the soil environment or for efficiency in moving minerals throughout plant tissues (Epstein and Jefferies, 1964). Greenleaf and Adams (1969) concluded that both factors likely influence fruit $\mathrm{Ca}$ concentration in different cultivars of tomato. With this vegetable crop, Behling et al. (1989) also showed that efficient use of Ca was associated with a higher ratio of soluble to insoluble forms of Ca throughout all plant tissues. Grusak et al. (1996) showed that a snap bean line with high pod $\mathrm{Ca}$ concentration had a greater capacity to partition more total plant $\mathrm{Ca}$ to pods than did a line with low pod $\mathrm{Ca}$, while both snap bean lines absorbed equivalent amounts of total plant Ca. It is impossible to determine whether differences observed among broccoli entries in this study are due to genetic variation in mineral uptake or mineral partitioning; both factors may play a role.

It is possible that genetically controlled factors other than those cited above have a large impact on $\mathrm{Ca}$ and $\mathrm{Mg}$ concentration in broccoli heads. With hybrids, there was a significant $(P<0.05)$ negative correlation between head $\mathrm{Ca}$ concentration and head weight and between head Mg concentration and head weight in both environments (Table 2). Since all heads harvested in this study had similar dimensions (i.e., a diameter of 10 to $12 \mathrm{~cm}$ and a length of $10 \mathrm{~cm}$ ), entries with greater head weight basically had a greater head density. Because heads with similar dimensions may exhibit similar rates of transpiration under comparable environmental conditions, the hybrids that develop denser heads may tend to have reduced $\mathrm{Ca}$ and $\mathrm{Mg}$ concentrations simply due to a dilution effect. This could occur as those hybrids with denser heads accumulate relatively more dry matter (primarily phloem delivered) without increasing $\mathrm{Ca}$ and $\mathrm{Mg}$ (primarily xylem-delivered) in the same relative proportion.

Using the mean squares from ANOVA for $\mathrm{Ca}$ and $\mathrm{Mg}$ concentrations of heads (Table 1), we computed the components of variance that are due to environmental, genotypic, and genotype by environment effects (data not presented). For hybrids, the resulting 
environmental and genotype by environment components of variance for $\mathrm{Ca}$ concentration were equal and both were ten times greater than that of the genotypic component of variance, while all three components of variance for $\mathrm{Mg}$ concentration were of a similar magnitude. With inbreds, environmental and genotypic components of variance were nearly equal for both $\mathrm{Ca}$ and $\mathrm{Mg}$ concentrations, while the genotype by environment component of variance was one quarter of the others in the case of $\mathrm{Ca}$ and essentially zero in the case of $\mathrm{Mg}$. Although the components of variance were only based on two environments, these results point to differences between inbreds and hybrids, and indicate that while it is likely that inbreds with consistently high or low $\mathrm{Ca}$ or $\mathrm{Mg}$ concentrations may be selected, consistent hybrids may be difficult to identify. Additional studies are needed to ascertain whether consistent mineral content of inbreds can be captured in a hybrid developed from them.

With inbreds, only $\mathrm{Mg}$ concentration was significantly correlated with head weight; Ca concentration was not correlated with head weight (Table 2). This again emphasizes that the dynamics of $\mathrm{Ca}$ and $\mathrm{Mg}$ concentration of inbred heads is not totally analogous to the dynamics for hybrids. Apparently, a dilution effect is occurring with $\mathrm{Mg}$ in inbred heads but a similar dilution is not occurring for $\mathrm{Ca}$. Additionally, there often were negative correlations between DTH and $\mathrm{Ca}$ and $\mathrm{Mg}$ concentrations, for both hybrids and inbreds. This is consistent with positive correlations observed between head weight and DTH, in that later maturing broccoli entries in this study tended to produce denser heads than earlier maturing entries.

Currently, the most successful commercial broccoli hybrids in the United States tend to have relatively late maturity (high DTH) and high head density. 'Marathon' exemplifies these characteristics and is generally considered to represent the industry standard. In our trials, 'Marathon' had consistently low concentrations of Ca and Mg (Table 3). It is possible that when breeders aim for a broccoli phenotype similar to that of 'Marathon', they select against high mineral concentration. Indeed, our results indicate indirectly that there may be a barrier to combining high head $\mathrm{Ca}$ or $\mathrm{Mg}$ concentration and head density in a single hybrid. Because Ca concentration of inbred heads was not significantly correlated with head weight, one can identify inbreds that exhibit high $\mathrm{Ca}$ concentration and relatively high head weight. However, it is uncertain if hybrids made using these specific inbreds will express those same characteristics. Future studies must determine this.

Results from this study indicate that efforts to improve $\mathrm{Ca}$ and $\mathrm{Mg}$ concentration of broccoli through genetic improvement may be impeded by the significant influence that the environment can have on ultimate concentrations, and also by potential negative linkages between mineral concentration and other traits such as head weight. In a recent paper, Quintana et al. (1999) concluded that environmental effects should not hinder breeding efforts to enhance Ca content of snap bean. That conclusion for snap bean, differs from our prediction for broccoli, emphasizing that efforts to enhance mineral concentration must be examined on a crop by crop basis. Our work makes a significant contribution by presenting a more realistic picture of the range in $\mathrm{Ca}$ or $\mathrm{Mg}$ concentrations that one might find in broccoli purchased and eaten by the consumer. Although there are a few commercial hybrids of broccoli that dominate the U.S. market, any broccoli purchased at random within the United States could have come from any of a large number of available hybrids; thus, $\mathrm{Ca}$ and $\mathrm{Mg}$ levels could be expected to vary by as much as 2 -fold.

\section{Literature Cited}

Behling, J.P., W.H. Gabelman, and G.C. Gerloff. 1989. The distribution and utilization of calcium by two tomato (Lycopersicon esculentum Mill.) lines differing in calcium efficiency when grown under low-Ca stress. Plant Soil 113:189-196.

Cook, W.P. and D.O. Ezell. 1983. Commercial broccoli production in South Carolina. Clemson Univ. Coop. Ext. Serv. Hort. Lflt. 52.

Epstein, E. and R.L. Jefferies. 1964. The genetic basis of selective ion transport in plants. Annu. Rev. Plant Physiol. 15:169-184.

Fairchild, L. 1999. Fresh trends. Vance Publ., Lenexa, Kans.

Farnham, M.W. 1998. Doubled haploid broccoli production using anther culture: Effect of anther source and seed set characteristics of derived lines. J. Amer. Soc. Hort. Sci. 123:73-77.

Giordano, L.B., W.H. Gabelman, and G.C. Gerloff. 1982. Inheritance of differences in calcium utilization by tomatoes under lowcalcium stress. J. Amer. Soc. Hort. Sci. 107:664-669.

Greenleaf, W.H. and F. Adams. 1969. Genetic control of blossomend rot disease in tomatoes through calcium metabolism. J. Amer. Soc. Hort. Sci. 94:248-250.

Grusak, M.A. 1994. Iron transport to developing ovules of Pisum sativum. I. Seed import characteristics and phloem iron-loading capacity of source regions. Plant Physiol. 104:649-655.

Grusak, M.A. and K.W. Pomper. 1999. Influence of pod stomatal density and pod transpiration on the calcium concentration of snap bean pods. J. Amer. Soc. Hort. Sci. 124:194-198.

Grusak, M.A., B.W. Stephens, and D.J. Merhaut. 1996. Influence of whole-plant net calcium influx and partitioning on calcium concentration in snap bean pods. J. Amer. Soc. Hort. Sci. 121:656659.

Heaney, R.P., C.M. Weaver, S.M. Hinders, B. Martin, and P.T. Packard. 1993. Absorbability of calcium from Brassica vegetables: Broccoli, bok choy, and kale. J. Food Sci. 58:1378-1380.

Heaney, R.P., C.M. Weaver, and R.R. Recker. 1988. Calcium absorbability from spinach. Amer. J. Clinical Nutr. 47:707-709. Johnston, C.C., Jr., J.Z. Miller, C.W. Slemenda, P.H. Teresa, K. Reister, M.S. Siu Hui, J.C. Christian, and M. Peacock. 1992. Calcium supplementation and increases in bone mineral density in children. New England J. Med. 327:82-87.

Li, Y. and W.H. Gabelman. 1990. Inheritance of calcium use efficiency in tomatoes grown under low calcium stress. J. Amer. Soc. Hort. Sci. 115:835-838.

Linder, M.C. 1991. Nutritional biochemistry and metabolism: With clinical applications. 2nd ed. Elsevier, New York.

Lucarini, M., R. Canali, M. Cappelloni, G. Di Lullo, and G. Lombardi-Boccia. 1999. In vitro calcium availability from Brassica vegetables (Brassica oleracea L.) and as consumed in composite dishes. Food Chem. 64:519-523.

Quintana, J.M., H.C. Harrison, J. Nienhuis, J.P. Palta, and M.A. Grusak. 1996. Variation in calcium concentration among sixty $S_{1}$ families and four cultivars of snap bean (Phaseolus vulgaris L.). J. Amer. Soc. Hort. Sci. 121:789-793.

Quintana, J.M., H.C. Harrison, J. Nienhuis, J.P. Palta, K. Kmiecik, and E. Miglioranza. 1999. Comparison of pod calcium concentration between two snap bean populations. J. Amer. Soc. Hort. Sci. 124:273-276.

Shils, M.E. 1996. Magnesium, p. 256-264. In: E.E. Ziegler and L.J. Filer, Jr. (eds.). Present knowledge in nutrition. 7th ed. ILSI Press, Wash., D.C.

U.S. Department of Agriculture-Agricultural research Service. 1998. USDA nutrient database for standard reference, release 12. Nutrient Data Laboratory Home Page, http://www.nal.usda.gov/ fnic/foodcomp. 